\title{
PERFORMANCE EVALUATION OF LOW PRESSURE DRIP-SUBUNIT UNDER DIFFERENT EMITTER TYPES AND DESIGN PARAMETERS
}

\author{
Mohamed A. Rashad*
}

\section{ABSTRACT}

Two experiments were conducted to evaluate the hydraulic performance of drip irrigation subunit designs using three emitter types $\left(E m_{1}, E_{2}\right.$; $\left.E_{3}\right)$. Each subunit consisted from one of three lateral lengths (20, 30 and 40m) which connects in open loop $(O L)$ and close loop $(C L)$. The results revealed that shortening the lateral length and close loop increase flow distribution uniformity (DU) for all emitter. There is a different effect of emitter types on the hydraulic performance of each loop at the three lateral lengths. Despite CL improves the hydraulic performance than $O L$, the effect was always limited. The main influence is attributable to the lateral length and emitter type.

Keywords: Low Pressure, Drip, Hydraulic Performance, Emitter, Uniformity.

\section{INTRODUCTION}

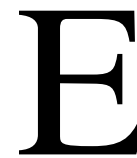
gypt is an arid area with low rainfall and high evaporation rates. Water is the main factor for the country development. Agriculture is mainly depending on irrigation, call for 50 to $85 \%$ of the total water use (Capra and Scicolone, 2004). The drip irrigation method is considered as the most efficient method requiring only 20 to $30 \%$ of water as compared to conventional methods (Tagar et al., 2010). Partial wetting of the soil volume, superior emission uniformity and a high level of control over water application facilitate efficient utilization of the limited water resources.

Drip systems are typically designed to operate at $100 \mathrm{kPa}$. Most rural communities in Egypt consist of smallholder farmers whose low income hinders adoption of a complex technology. However, most of drip irrigation systems in Egypt were using low-pressure to save energy (Harby and Hans-Heinrich, 2013).

${ }^{*}$ Lecturer, Agric. Eng. Dept., Fac. of Agric., Suez Canal Univ., Egypt. 
The combination of laterals and manifold pipe constitute a hydraulic subunit. The design process is used to reduce the friction-induced pressure changes in the lateral to achieve an acceptable level of emitter discharge variation (Phocaides, 2000).

Small differences between emitters may result in significant discharge variations (Kirnak et al., 2004). The selection of emitters is difficult because there are a variety of emitter characteristics to be considered in relation to crop, soil and topography, emitter price and hydraulic performance of the system (Rashad, 2006). Therefore, the objective of this study was to improve the hydraulic performance of low pressure drip irrigation subunit under Egyptian conditions.

\section{MATERIALS AND METHODS}

Two experiments were carried out in agriculture faculty, Suez Canal University to calibrate emitters' hydraulic characteristics and to evaluate the hydraulic performance of subunit designs.

\section{Emitter Hydraulic Evaluation:}

The first experiment was to calibrate hydraulic characteristics of a three commonly used emitters in the local market (table 1). The emitters $E m_{l}$ and $E m_{2}$ were globally used with relatively high prices, where $E m_{3}$ was locally manufactured and commonly used by the farmers in Egypt, due to its cheap price. The three emitters discharge were measured at five operation pressures of $20,50,80,100$ and $120 \mathrm{kPa}$ in three replications. The test bench was closed system and constructed to allow testing of 40 emitters simultaneously by using fresh water. The equation for Pressureflow relationship that has been used by Keller and Karmeli (1974) and many researchers can be expressed as:

$$
q=k h^{x} \quad \rightarrow(1)
$$

Where $q$ : emitter discharge rate $(\ell / h), h:$ pressure head at the entry of the emitters $(\mathrm{m}), k$ : dimensionless constant of proportionality that characterizes each emitter, and $x$ : dimensionless emitter discharge exponent which characterizes the flow regime. 
The emitter manufacturer's coefficient of variation was calculated by measuring the discharge from a sample of the new emitters after ASABE EP405.1 (2008) as follows:

$$
C_{V}=\frac{S}{\bar{x}} \quad \rightarrow(2)
$$

Where $C_{V}$ : manufacturer's coefficient of variation (Dimensionless); $S$ : the standard deviation of the emitters discharge in the sample $(\ell / h)$, and $\bar{\chi}$ : emitter's discharges mean $(\ell / \mathrm{h})$.

\section{Evaluation the Subunit Hydraulic Performance:}

The second experiment was conducted to evaluate the hydraulic performance of drip irrigation subunit designs (Fig. 1). Fresh water was pumped to the experiment by a $1.5 \mathrm{HP}$ pump. A ball valve, flow meter and a pressure gauge (0.6bar) with an increment of $2 \mathrm{kPa}$ were attached to the entrance of every manifold line (to control the discharge and the pressure under 20kPa). Sub main pipe PE (low density polyethylene) with inside diameter (I.D) of $54.50 \mathrm{~mm}$ was branched to two groups of subunit designs (three subunits in each group) for each emitter. Three PE laterals (14.50mm I.D) from each length of 20, 30 and 40m were connected with each PE manifold pipe (25.25mm I.D) on a level terrain. These laterals loop were open in the first group, and closed in the second group. The distance between lateral lines was $1 \mathrm{~m}$ with emitter spacing of $50 \mathrm{~cm}$.
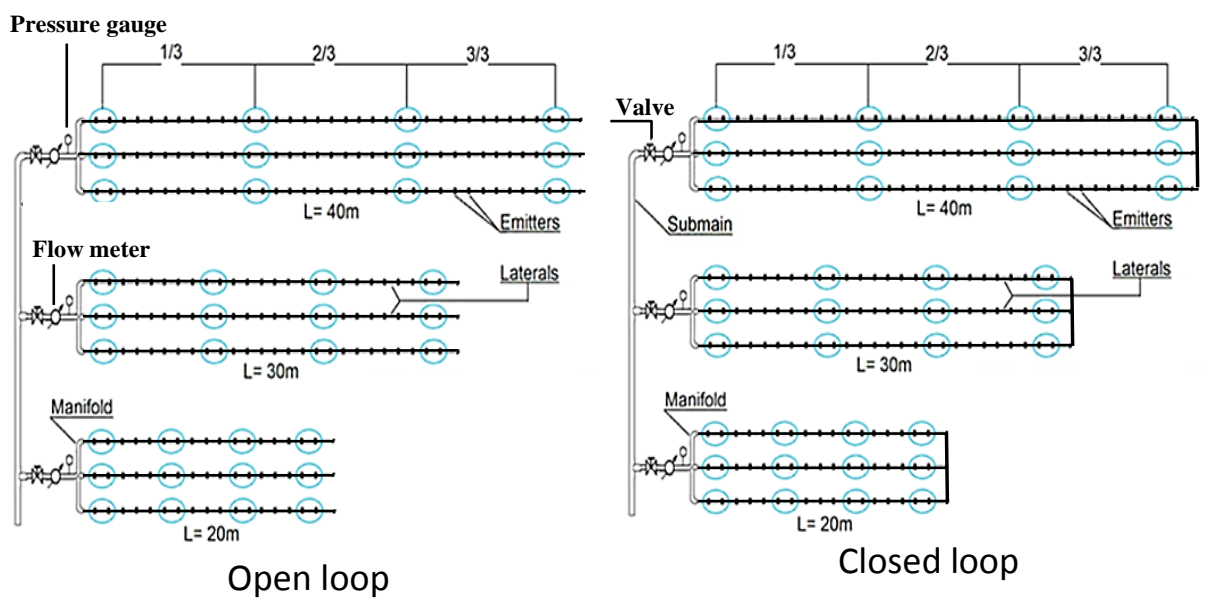

Figure (1): Schematic diagram of the subunit designs with locations of testing for each emitter type. 
Pressure variation $P_{v a r}$ compares maximum and minimum pressure along a single lateral as:

$$
P_{v a r}=\frac{\left(P_{\max }-P_{\min }\right)}{P_{\max }} \times 100 \quad \cdots
$$

Where $P_{\max }$ and $P_{\min }$ : maximum and minimum emitter pressure $(\mathrm{kPa})$, respectively.

The emitter discharge variation $q_{v a r}$ calculated in the same manner of $P_{v a r}$. The desirable $q_{v a r}$ according to (Clark et al., 2007); is less than $10 \%$ (approximately $20 \%$ for variation in pressure) for the design of lateral line. The acceptable variations ranged from $10 \%$ to $20 \%$, (approximately fallen in $20 \%$ to $40 \%$ range variation in pressure), while, the unacceptable variation is more than $20 \%$ (approximately $40 \%$ for variation in pressure). Distribution Uniformity $(D U)$ is a common index for uniformity application. The excellent $D U$ values were above $90 \%$, good between 90 to $80 \%$, fair between 80 to $70 \%$, poor between 70 to $60 \%$, and unacceptable below 60\% (ASABE EP405.1, 2008). Two contiguous emitters were selected on each lateral at four locations (at the inlet, 1/3, $2 / 3$ and the far end of the lateral) measured as representative sample of flow rate as shown in Fig. 1. The sample of flow rate was calculated as (Jiang and Kang, 2010):

$$
D U=\left(\frac{q_{l q}}{q_{a}}\right) \times 100 \rightarrow(4)
$$

Where $q_{l q}$ : the mean discharge of the lowest one-fourth of emitter flow rates, $\ell / \mathrm{h}$, and $q_{a}$ : the mean discharge of all the sampled emitters, $\ell / \mathrm{h}$.

\section{RESULTS AND DISCUSSION}

\section{Emitter Hydraulic Characteristics:}

Table (1) shows the main hydraulic properties of the calibrated emitter types such as nominal and measured flow rate, difference percentage between nominal and measured discharge, emitter discharge equation constants $(k, x)$, flow regime; the manufacturer's coefficient of variation $(C v)$ and its classifications according to ASABE EP405.1 (1988). 
Table (1): The main hydraulic characteristics of emitter types.

\begin{tabular}{|c|c|c|c|c|c|c|c|c|c|}
\hline \multicolumn{2}{|c|}{ Emitter } & \multicolumn{2}{|c|}{$\mathrm{q}(\ell / \mathrm{h})$} & Diff. & \multicolumn{2}{|c|}{ constants } & \multirow{2}{*}{ Type } & \multicolumn{2}{|c|}{$(C v)$} \\
\cline { 1 - 4 } \cline { 9 - 11 } Symbol & Trademark & Nom. ${ }^{(1)}$ & Meas. & $(\%)$ & $K$ & $X$ & & Value & Classify. \\
\hline$E m_{1}$ & Katif & 3.75 & 4.01 & 6.93 & 7.60 & -0.14 & $\mathrm{PC}^{(2)}$ & 0.06 & Average \\
\hline$E m_{2}$ & Turbo Key & 4.00 & 4.22 & 5.50 & 0.54 & 0.45 & $\mathrm{~T}^{(3)}$ & 0.13 & Marginal \\
\hline$E m_{3}$ & Metallic & 4.00 & 29.6 & 640 & 2.06 & 0.57 & $\mathrm{~T}$ & 0.28 & Unacceptable \\
\hline
\end{tabular}

(1) = Nominal discharge at100kPa, (2) =Pressure Compensating, (3) =Turbulent Flow.

The emitter exponent ( $x$ ) for $E m_{1}$ was a negative number close to zero (0.14). Where, the $x$ values were 0.45 and 0.57 for $E m_{2}$ and $E m_{3}$, respectively. The results of $x$ were agreed with the emitter manufacturer's classification. $C v$ was on the same classification under different operating pressures with the three emitter types. $C v$ evaluation was average, marginal and unacceptable with $E m_{1}, E m_{2}$ and $E m_{3}$ respectively.

\section{Subunit Hydraulics Performance:}

Pressure variation $\left(\boldsymbol{P}_{v a r}\right)$. Figure 2-A showed $P_{\text {var }}$ under the two Lateral loops at three lengths using $E q$. (3). $P_{\text {var }}$ of $E m_{1}$ under $O L$ and $C L$ was 5, $25 ; 38.35 \%$ and $5,20.85 ; 31.65 \%$ at 20,$30 ; 40 \mathrm{~m}$ lateral lengths, respectively. It was desirable classification at $20 \mathrm{~m}$ and acceptable at $30 \mathrm{~m}$; $40 \mathrm{~m}$ lateral lengths under both loops. $E m_{2}$ under $O L$ and $C L$ were 5, $18.35 ; 21.65$ and $3.35,10.85 ; 12.5$ at 20,$30 ; 40 \mathrm{~m}$ lateral lengths, respectively. $P_{v a r}$ was desirable for all lateral lengths under both loops. $P_{v a r}$ of $E m_{3}$ under $O L$ and $C L$ were 51.65, 60, 64.15 and 50, 53.35, 54.15 at lateral lengths of 20,30 and 40m, respectively. All $P_{v a r}$ values of $E m_{3}$ were classified as unacceptable. $P_{v a r}$ was increased by lateral length increasing for all emitter types under the two loops. $P_{v a r}$ under $C L$ were lower than $O L$ at the three lateral lengths for all emitter types. $P_{v a r}$ was in the following descending order $\left(E m_{3}>E m_{1}>E m_{2}\right)$ at the three lateral lengths under the two loops.

The average discharge $\left(\boldsymbol{q}_{\boldsymbol{a}}\right)$. Average discharge of $E m_{1}$ under $O L$ and $C L$ was $4.41,4.36 ; 3.80 \ell / \mathrm{h}$ and $4.50,4.44 ; 3.85 \ell / \mathrm{h}$ at 20,$30 ; 40 \mathrm{~m}$ lateral lengths, respectively. 

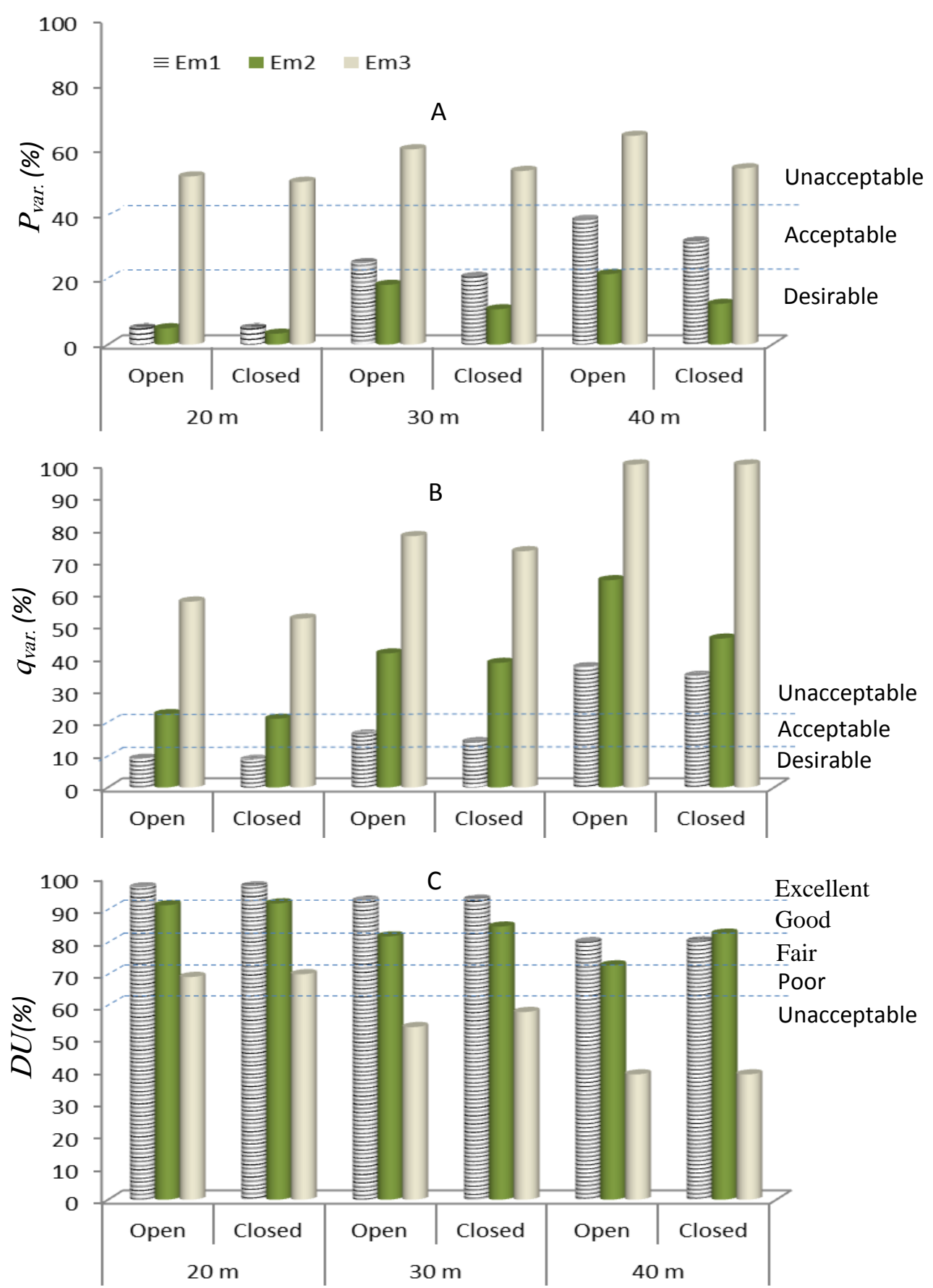

Figure (2): The effect of lateral length, emitter type and subunit loop on the pressure variation $P_{v a r}(\%)$, discharge variation $q_{v a r}(\%)$ and distribution uniformity $D U(\%)$. 


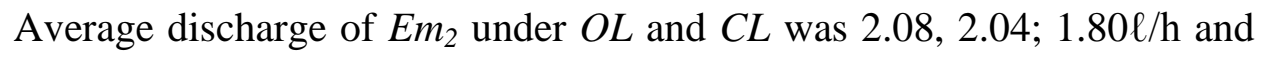
$2.08,2.05 ; 1.88 \mathrm{l} / \mathrm{h}$ at 20,$30 ; 40 \mathrm{mlateral}$ lengths respectively. Average discharge of $E m_{3}$ under $O L$ and $C L$ were 9.11, 7.84; 7.30 $/ \mathrm{h}$ and 9.52, $7.93 ; 7.30 \ell / h$ at 20,$30 ; 40 \mathrm{~m}$ lateral lengths, respectively. Average discharge values were slightly increased under $C L$ than $O L$ and proportionally decreased by lateral length increasing under the both loops for all emitter types.

Emitter discharge variation $\left(\boldsymbol{q}_{v a r}\right)$. Discharge variation under different treatments showed in (Fig. 2-B). Discharge variation of $E m_{1}$ in $O L$ and $C L$ was $8.95,16.42 ; 37.28 \%$ and $8.62,14.10 ; 34.53 \%$ at 20,$30 ; 40 \mathrm{~m}$ lateral lengths, respectively. Discharge variation was classified as desirable, acceptable and unacceptable at 20, 30 and 40m lengths, respectively under the two loops. Discharge variation of $E m_{2}$ under $O L$ and $C L$ were $22.72,41.51 ; 64.18 \%$ and $21.27,38.59 ; 46.09 \%$ at 20,30 ; $40 \mathrm{~m}$ lengths, respectively. All the flow variation percentages for $E m_{2}$ were higher than 20\%, which classified as unacceptable. Discharge variation for $E m_{3}$ under $O L$ and $C L$ were 57.55, 77.82; 100.0\% and 52.29, $73.16 ; 100.0 \%$ at 20,$30 ; 40 \mathrm{~m}$ lengths, respectively which classified as unacceptable. The $C L$ has lower $q_{v a r}$ than the $O L$ at all lateral lengths for all emitter types. Discharge variation increased by increasing lateral length for all emitter types under the two loops. In conclusion emitters $E m_{3}$ and $E m_{2}$ were turbulent flow (TF) with low $C v$ classification, while $E m_{1}$ was pressure compensating and had average $C v$. The effect of emitter types on $q_{v a r}$ dissimilar the effect on $P_{v a r}$ and could be stated in the following descending order: $E m_{3}>E m_{2}>E m_{1}$.

Distribution uniformity $(\boldsymbol{D U})$ showed in Figure 2-C, for $E m_{1}$ under $O L$ and $C L$ were $96.73,92.61 ; 79.79 \%$ and $97.03,92.95 ; 80.01 \%$ at 20,30 ; $40 \mathrm{~m}$ lateral lengths, respectively. $E m_{l}$ has an excellent $D U$ at $20 ; 30 \mathrm{~m}$ and good at $40 \mathrm{~m}$ lateral lengths under both loops. $D U$ of $E m_{2}$ under OL and CL was $91.16,81.52 ; 72.53 \%$ and $91.72,84.55 ; 82.37 \%$ at 20,$30 ; 40 \mathrm{~m}$ lateral lengths, respectively. $D U$ at $20 \mathrm{~m}$ and $30 \mathrm{~m}$ lengths were excellent and good, respectively under the two loops, whereas $D U$ was fair and 
good at $40 \mathrm{~m}$ under $O L$ and $C L$, respectively. The $D U$ of $E m_{3}$ under $O L$ and $C L$ were $68.94,53.43 ; 38.79 \%$ and $69.78,58.11 ; 38.79 \%$ at 20,30 ; $40 \mathrm{~m}$ lateral lengths, respectively. $D U$ at $20 \mathrm{~m}$ was poor and unacceptable at 30; 40m lengths under the two loops. The $C L$ had higher distribution uniformity than the $\mathrm{OL}$ at 20 and $30 \mathrm{~m}$ lateral lengths. It is noted that the length of $40 \mathrm{~m}$ showed identical $D U$ percentages; due to absence of water pressure at the lateral outlet ends.

\section{CONCLUSIONS}

The results show that global emitters $E m_{1}$ and $E m_{2}$ were pressure compensating with average $C_{V}$ and turbulent flow with marginal $C_{V}$, respectively. On the other hand local emitter $\mathrm{Em}_{3}$ was turbulent flow with unacceptable $C_{V}$. Distribution Uniformity $(D U)$ of $E m_{1}$ was excellent with all lateral lengths. $D U$ of $E m_{2}$ was decreased from excellent with $20 ; 30 \mathrm{~m}$ to good with $40 \mathrm{~m}$ lateral length. While $D U$ of $E m_{3}$ was decreased from fair to unacceptable by increasing lateral length more than $20 \mathrm{~m}$. $D U$ was increased while $P_{v a r}$ and $q_{v a r}$ were decreased with close loop $(C L)$ and short lateral length compared with open loop $(O L)$ and long lateral length for all emitters. The study concluded that the lateral length and emitter type are the main influence parameters. Although there are hydraulic limited benefits for $C L$, it may have added some advantages such as facilitating washing laterals.

\section{REFERENCES}

ASABE STANDARDS, (2008). Design and installation of microirrigation systems. ASAE EP405.1 APR1988: 1-5.

Capra, A. and B. Scicolone, (2004). Emitter and filter tests for waste water reuse by drip irrigation. Agric. Water Management, (68): 135-149.

Clark, G. A.; D. Haman; J. F. Prochaska and M. Yitayew, (2007). Micro Irrigation for Crop Production (General system design principles). Elsevier: 161-215. 
Harby, M. and T. Hans-Heinrich (2013). On-farm evaluation of lowpressure drip irrigation system for smallholders. Soil \& Water Res., 8, 2013 (2): 87-95.

Jiang, S. and Y. Kang, (2010). Evaluation of micro-irrigation uniformity on laterals considering field slopes. J. of irrigation and drainage engineering: 429-434.

Keller, J. and D. Karmeli, (1974). Trickle irrigation design parameters. Transaction of the ASAE, Vol., 17(4): 678-684.

Kirnak, H.; E. Dogan; S. Demir and S. Yalcin, (2004). Determination of hydraulic performance of trickle irrigation emitters used in irrigation systems in the Harran Plain. Turk. J. Agric. Forest., (28): 223-230.

Phocaides, A., (2000). Technical Handbook On Pressurized irrigation techniques. Food and Agriculture Organization of the United Nation: 1-50.

Rashad, M. A. (2006). A study on emitter performance under some operation condition. Unpublished Ph.D Thesis, Ismailia, Egypt: Suez Canal University, Dep. of Agric. Engineering.

Tagar, A. A.; M. S. Mirjat; A. Soomro and A. Sarki, (2010). Hydraulic performance of different emitters under varying lateral lengths., Pak. J. Agri., Agric. Eng., Vet. Sci., 26 (2): 48-59.

\section{الملخص العربى}

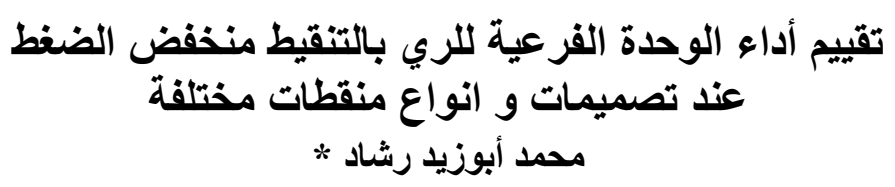

تهدف هذه الدراسة لتحسين الأداء الهيدروليكي للوحدة الفرعية للري بالتنقيط منخفضة الضغط

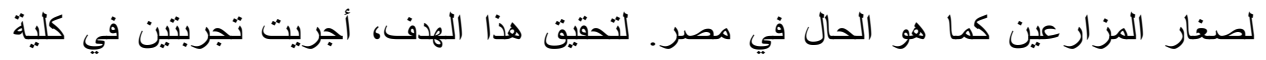

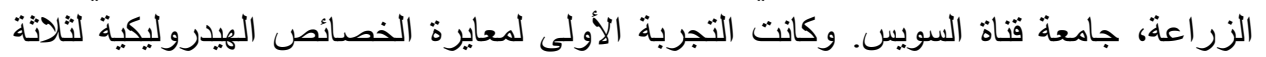

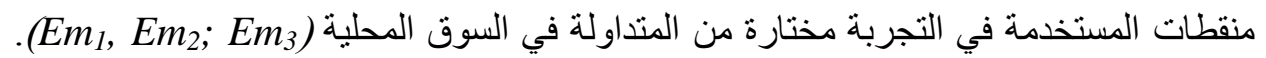
حيث كانت المنقطات متوسط و مضطرب السريان بمعامل

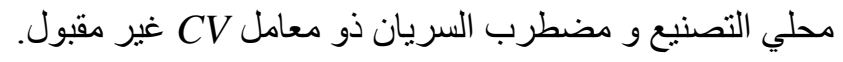
* مدرس - قسم الهندسة الزراعيةـ كلية الزراعة ـ جامعة قناة السويس. 
ثاني تجربة كانت تهدف لتقييم الأداء الهيدروليكي لعدة تصاميم للوحدة الفرعية تحت ضغط

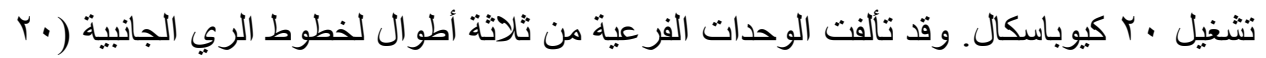
و • ب و • ع م) لكل نوع منقط في نظام مفتوح OL Oتهايات الخطوط غير متصلة) و نظام مغلق CL (متصلة النهايات). و أظهرت النتائج أن تقصير طول الخطوط الجانبية و استخدام

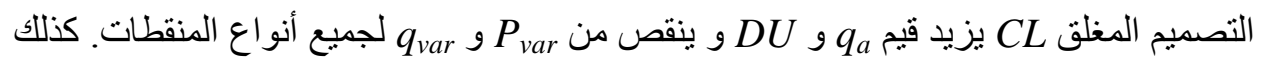

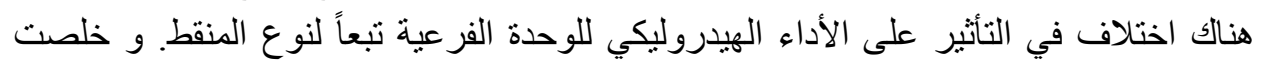

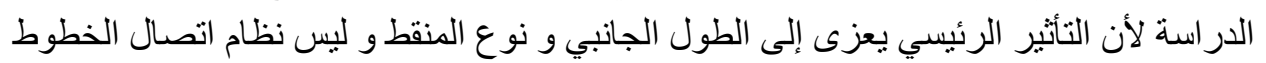

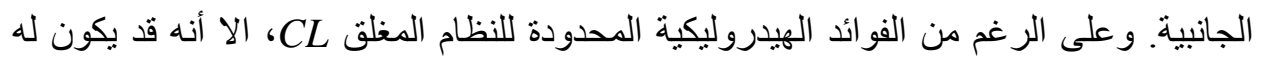
بعض المزايا الاخرى كتسهيل غسيل الخطوط الجانبية. 